\title{
Web based Clinical Data Management System
}

\author{
Parimal Tergundi $^{1}$, Prajnya Baliga ${ }^{2}$, Nilam Kamble ${ }^{3}$, Poonam Patil ${ }^{4}$, Nikita Raval ${ }^{5}$ \\ Professor, Computer Science and Engineering, KLS Gogte Institute of Technology, Belgaum, India ${ }^{1}$ \\ Student, Computer Science and Engineering, KLS Gogte Institute of Technology, Belgaum, India ${ }^{2,3,4,5}$
}

\begin{abstract}
Web Based Clinical Data Management System" mainly keeps track of all the patient records of the patients that have taken services from the hospital that uses this system. All the work that was done manually before, like making appointments, storing patient data, getting test reports from test centres, etc. can be done using this system. Apart from these features, the system also reduces manual work on the admin by generating reports like the collection of money made for the day and the number of patients that came into the hospital to endure services for a given day. Moreover the entire project is a web based application, thereby making resources like test reports, patient symptoms and prescriptions available to the doctor in real-time. As it is web based, information stored in the server is easily accessible anywhere and at anytime. Resources can be easily managed and maintained with this system. It provides status of every resource which helps administrators and other staff using this system to manage them effectively and efficiently.
\end{abstract}

Keywords: Management, Automation, Clinical, Web.

\section{INTRODUCTION}

Web Based Clinical Data Management System is developed to support and automate the clinic daily operation. Clinic Management System is a system that can help the clinic to manage their daily activity. This system will involve all the clinic operation starting from patient registration until billing the patient. Here the patients can register online and get their appointment. This system helps reduce the problems that occur when using the manual system. The important thing is it will become easier for data record and retrieval. This software also stores all the patient details, patients lab reports, bill calculation, billing, monthly reports and daily reports. This system enables doctors and clinic assistant to manage patient records, make appointments and produce reports. This system also generates report regarding the clinic operation. User can enter the patient details. Whatever treatment he has taken will also be saved in the database. Other than that, the system is user friendly and it can help the clinic to manage their activity.

The target user for this system is staff of the clinic, doctor and also the management. Other than that, the system is user friendly and it can help the clinic to manage their activity. Overall this system is able to support the daily clinic operation based on evaluation from real user and the system is able to perform the task correctly. The patient gets the treatment and data about the treatment is recorded into the system. The system has few modules such as hospital, doctor, reception staff and pathological lab staff.

\section{SYSTEM DESIGN AND SOFTWARE MODEL}

\section{CONTEXT LEVEL DATA FLOW DIAGRAM}

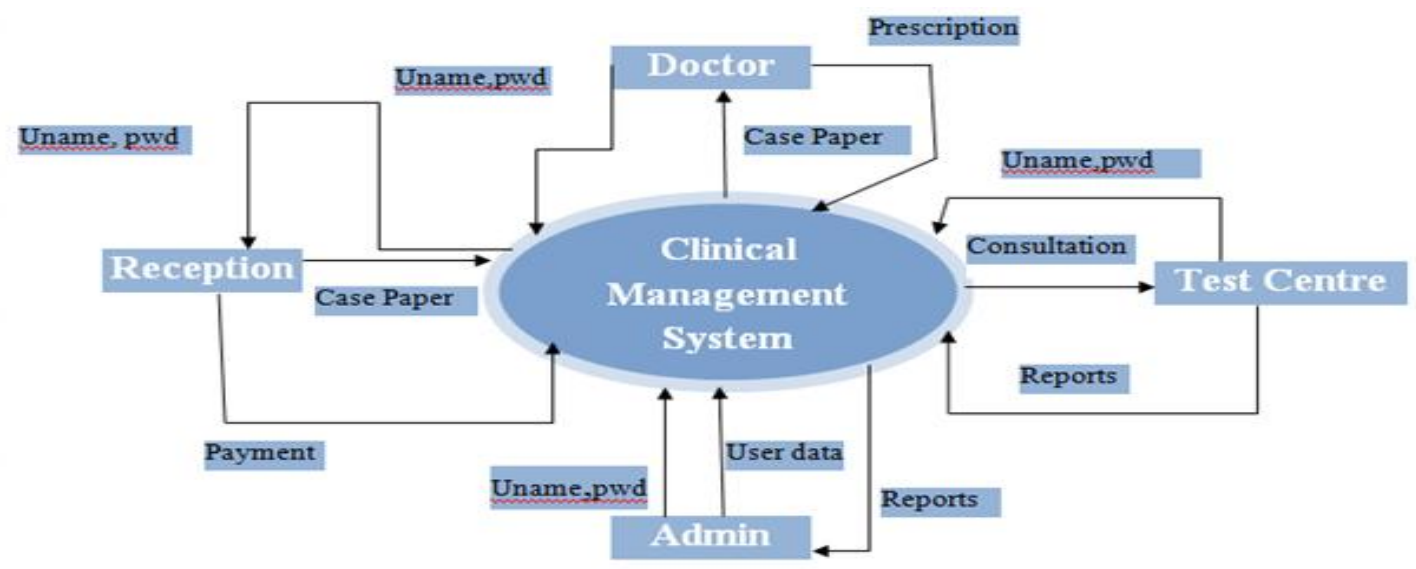

Fig. 1 Context Level DFD 
The above figure shows the Context DF Diagram shows the overview of the resource management process. There are different tables where the data of resource is stored. There is also a table that stores the resource details. This diagram also shows the relationship between the tables and their association.

B.DATA FLOW DIAGRAM

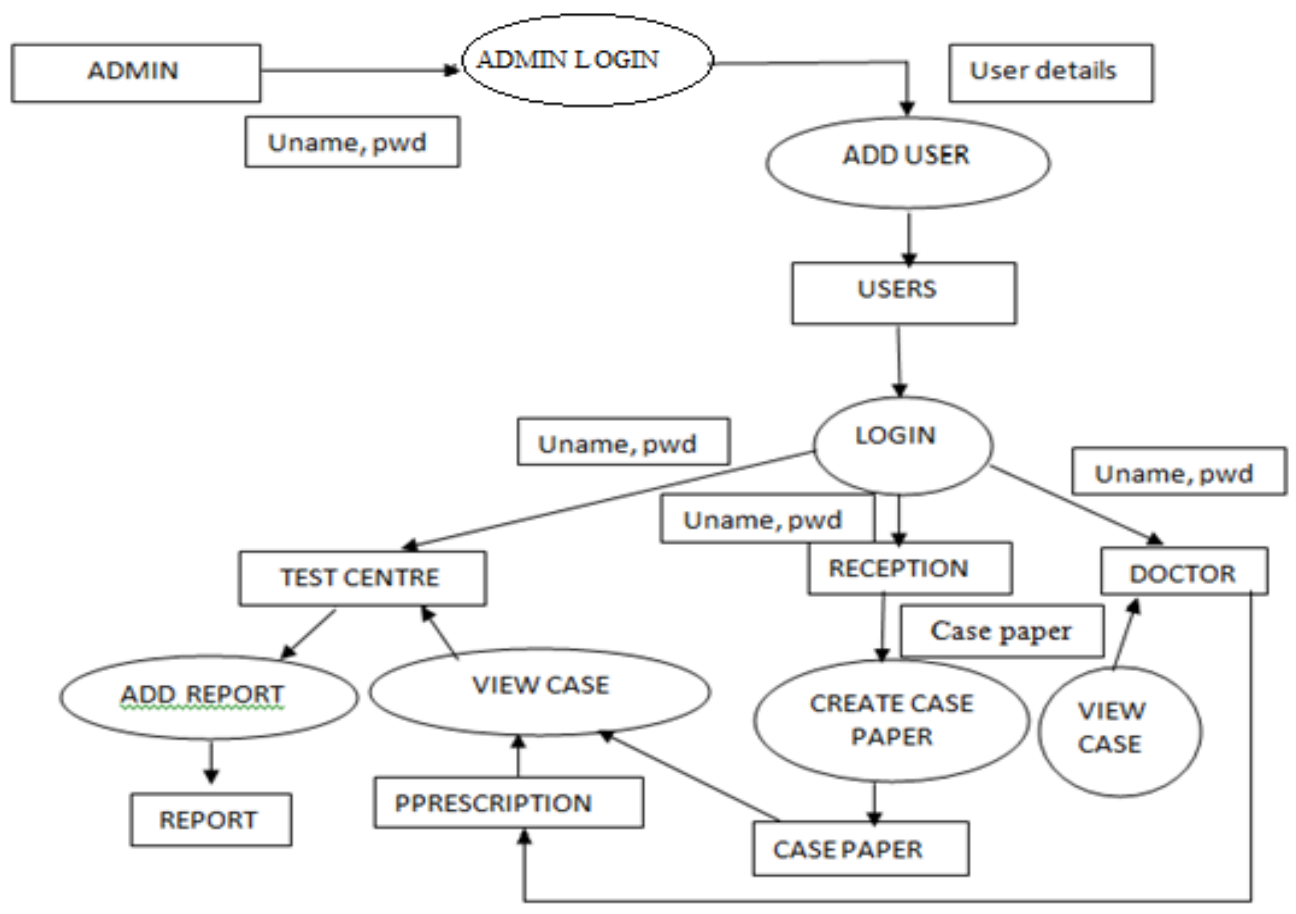

Fig. 2 DFD

\section{ENTITY-RELATIONSHIP DIAGRAM}

An entity-relationship model (ER model) describes inter-related things of interest in a specific domain of knowledge. An ER model is composed of entity types (which classify the things of interest) and specifies relationships that can exist between instances of those entity types.

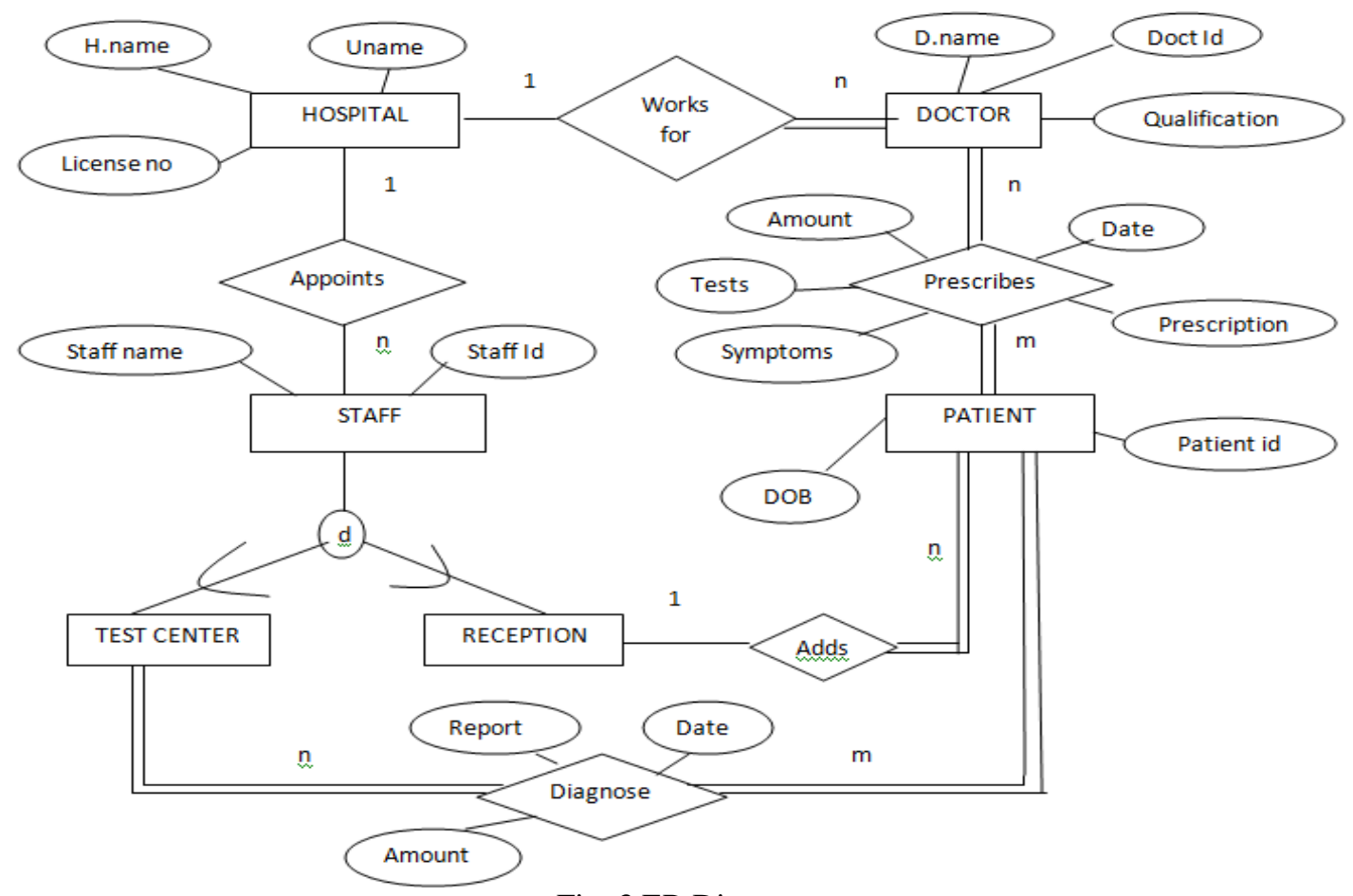

Fig. 3 ER Diagram 
Vol. 6, Issue 6, June 2017

\section{SEQUENCE DIAGRAM}

A sequence diagram is an interaction diagram that shows how objects operate with one another and in what order. It is a construct of a message sequence chart. A sequence diagram shows object interactions arranged in time sequence. It depicts the objects and classes involved in the scenario and the sequence of messages exchanged between the objects needed to carry out the functionality of the scenario. Sequence diagrams are typically associated with use case realizations in the Logical View of the system under development. Sequence diagrams are sometimes called event diagrams or event scenarios.A sequence diagram shows, as parallel vertical lines, different processes or objects that live simultaneously, and, as horizontal arrows, the messages exchanged between them, in the order in which they occur. This allows the specification of simple runtime scenarios in a graphical manner.

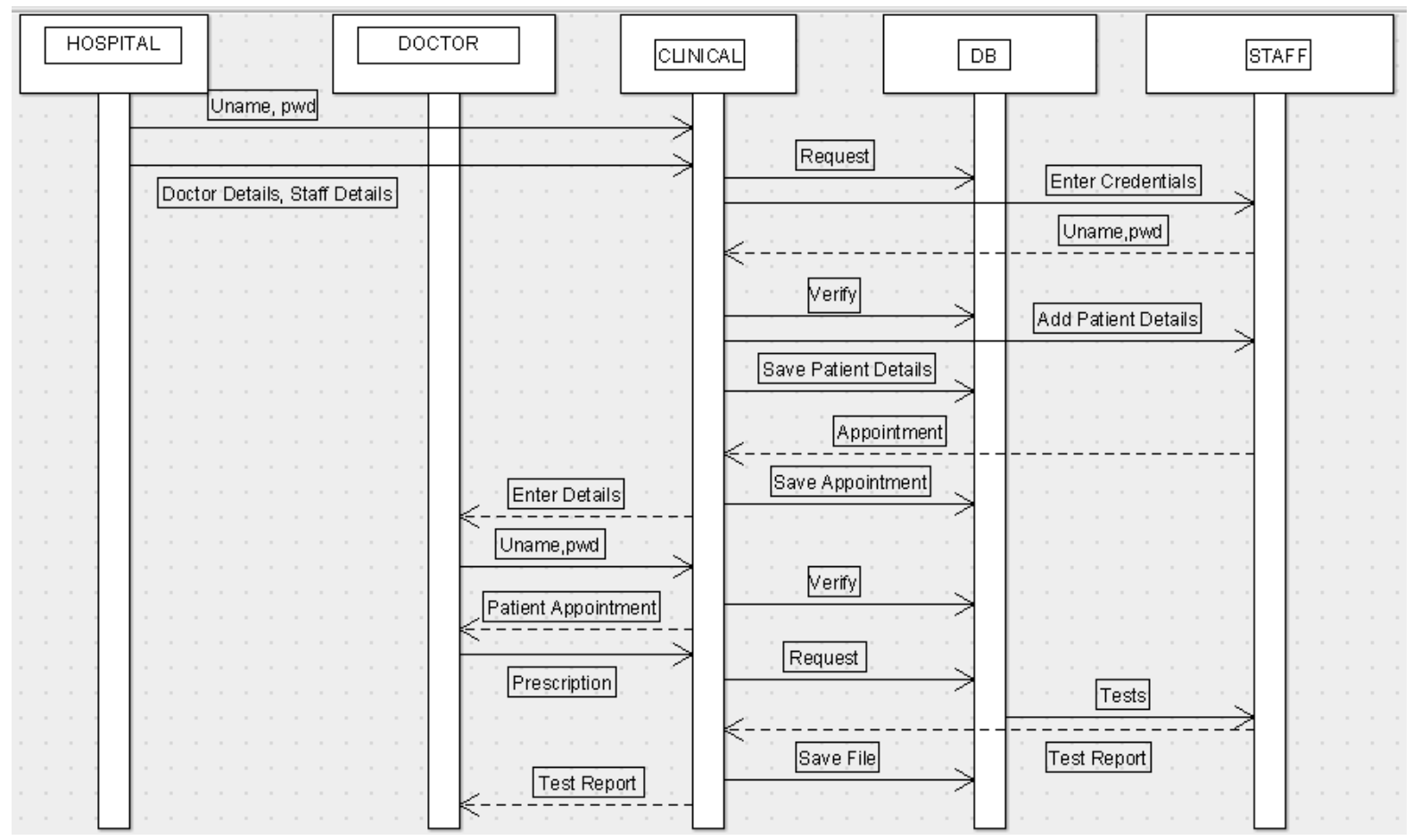

Fig. 4 Sequence Diagram

\section{E.WATERFALL DEVELOPMENT MODEL}

Waterfall development model is a popular version of system development life cycle model for system engineering. It often considered as classis approach to the system development life cycle and it is a linear and sequential development method (Margaret Rouse, 2007). Waterfall model basically aid developers to develop a high quality system step by step. The uniqueness of this model is developers have to be complete a stage before process to next stage and it cannot return to previous stage after process to next stage. The stages of waterfall model are shown in the figure below.

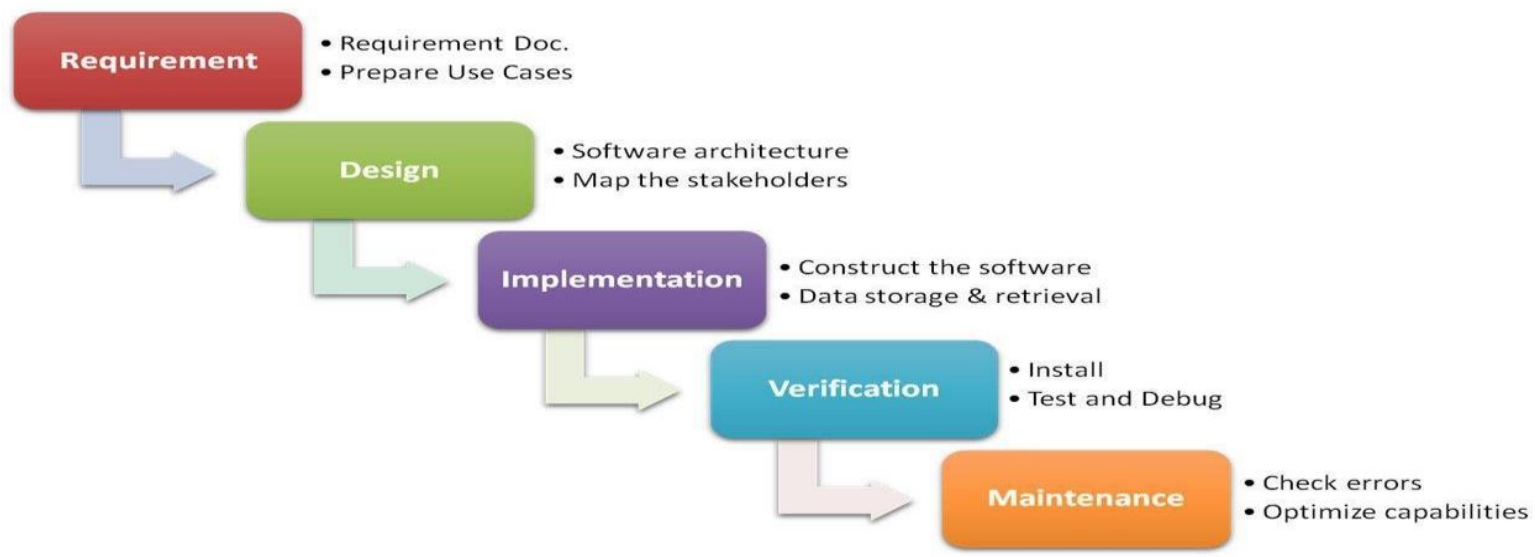

Fig. 5 Waterfall Development Model 
The waterfall model has few advantages; it consists of detailed requirement which can be identified earlier before proceeding to the next stage to prevent the change of requirement. The waterfall model is common models which are used by the developers due to its simplicity and it is easy to understand. The detailed description in every stage helps the new members in the development team to understand the software better so that they could carry on with their task as soon as possible. However, there are some disadvantages in using waterfall model. Changing the requirement in the later stage is not possible as it might incur a very high cost. The time taken to go from a stage to another stage is very long which might cause delay in the project. Other than that, the user involvement is very low where feedback from the user is not available.

\section{III.IMPLEMENTATION DETAILS}

\section{A.TRIPLE ENCRYPTION ALGORITHM}

In cryptography, Triple DES (3DES), officially the Triple Data Encryption Algorithm (TDEA or Triple DEA), is a symmetric-keyblock cipher, which applies the Data Encryption Standard (DES) cipher algorithm three times to each data block.The original DES cipher's key size of 56 bits was generally sufficient when that algorithm was designed, but the availability of increasing computational power made brute-force attacks feasible. Triple DES provides a relatively simple method of increasing the key size of DES to protect against such attacks, without the need to design a completely new block cipher algorithm. Triple DES uses a "key bundle" that comprises three DES keys, $\mathrm{K}_{1}, \mathrm{~K}_{2}$ and $\mathrm{K}_{3}$, each of 56 bits (excluding parity bits). The encryption algorithm is:

ciphertext $=\mathrm{E}_{\mathrm{K} 3}\left(\mathrm{D}_{\mathrm{K} 2}\left(\mathrm{E}_{\mathrm{K} 1}(\right.\right.$ plaintext $\left.\left.)\right)\right)$

I.e., DES encrypt with $K_{1}$, DES decrypt with $K_{2}$, then DES encrypt with $K_{3}$.

Decryption is the reverse:

plaintext $=\mathrm{D}_{\mathrm{K} 1}\left(\mathrm{E}_{\mathrm{K} 2}\left(\mathrm{D}_{\mathrm{K} 3}(\right.\right.$ ciphertext $\left.\left.)\right)\right)$

I.e., decrypt with $\mathrm{K}_{3}$, encrypt with $\mathrm{K}_{2}$, then decrypt with $\mathrm{K}_{1}$.

Each triple encryption encrypts one block of 64 bits of data.

In each case the middle operation is the reverse of the first and last. This improves the strength of the algorithm when using keying option 2, and provides backward compatibility with DES with keying option 3 .

\section{B.SEARCH ALGORITHM}

A search algorithm is an algorithm that retrieves information stored within some data structure. Data structures can include linked lists, arrays, search trees, hash tables, or various other storage methods. The appropriate search algorithm often depends on the data structure being searched. Searching also encompasses algorithms that query the data structure, such as the SQL SELECT command.

Search algorithms can be classified based on their mechanism of searching. Linear search algorithms check every record for the one associated with a target key in a linear fashion. Binary, or half interval searches, repeatedly target the center of the search structure and divide the search space in half. Comparison search algorithms improve on linear searching by successively eliminating records based on comparisons of the keys until the target record is found, and can be applied on data structures with a defined order. Digital search algorithms work based on the properties of digits in data structures that use numerical keys. Finally, hashing directly maps keys to records based on a hash function. Searches outside of a linear search require that the data be sorted in some way. Search functions are also evaluated on the basis of their complexity, or maximum theoretical run time.

\section{TESTING}

Software testing is a process used for verifying the correctness, completeness and quality of the developed software. Software is built out of sub-systems that are composed of modules, which in turn are composed of procedures and functions. The sequence of testing activities performed for the tracking system is Unit Testing and System Testing.

\section{A.UNIT TESTING}

There exist a number of components in every sub-system. Every component is tested using respective test procedures. Each component is tested individually based on their needs. Unit test focuses verification effort on the smallest unit of the software design component. The individual components like the sensors, capacitors, microcontroller, resistors, digital display etc. are tested individually for their power and use. To check whether they are compatible with the whole system unit testing is carried out.

\section{B.SYSTEM TESTING}

System testing is the stage of implementation. Testing is the process of executing a program with the intent of finding an error. A good test case is one that has a high probability of finding a yet undiscovered error. The whole system is 
being tested to check whether the system works as per the requirements and consist of error if any. With different test cases for sensors the test is carried out.

\section{C.TEST CASES}

The following few tests were carried out for the software and are demonstrated in the table below:

\begin{tabular}{|c|c|c|c|c|c|c|c|}
\hline $\begin{array}{l}\text { Test Case } \\
\text { No. }\end{array}$ & $\begin{array}{l}\text { Test Demo } \\
\text { for }\end{array}$ & \multicolumn{3}{|l|}{ Input } & Expected Behaviour & Result Obtained & $\begin{array}{l}\text { Concl } \\
\text { usion }\end{array}$ \\
\hline 1. & Login & Blank & \multicolumn{2}{|c|}{$* * * * *$} & Enter the username & Enter the username & Valid \\
\hline 2. & Login & Kavya & \multicolumn{2}{|c|}{ Blank } & Enter the password & Enter the password & Valid \\
\hline \multirow[t]{2}{*}{3.} & \multirow[t]{2}{*}{ Registration } & Password & \multicolumn{2}{|c|}{$\begin{array}{l}\text { Confirm } \\
\text { Password }\end{array}$} & \multirow[t]{2}{*}{$\begin{array}{l}\text { Password does not } \\
\text { match }\end{array}$} & \multirow[t]{2}{*}{$\begin{array}{l}\text { Password does not } \\
\text { match }\end{array}$} & \multirow[t]{2}{*}{ Valid } \\
\hline & & \multicolumn{3}{|l|}{123456789} & & & \\
\hline 4. & $\begin{array}{l}\text { Registration } \\
\text { of already } \\
\text { existing } \\
\text { entity }\end{array}$ & \multicolumn{3}{|l|}{ Prithvi } & $\begin{array}{l}\text { Doctor already } \\
\text { exists }\end{array}$ & $\begin{array}{l}\text { Doctor already } \\
\text { exists }\end{array}$ & Valid \\
\hline 5. & $\begin{array}{l}\text { Mobile } \\
\text { number } \\
\text { validation }\end{array}$ & \multicolumn{3}{|l|}{1234567890} & $\begin{array}{l}\text { Please enter mobile } \\
\text { numbers starting } \\
\text { from } 7,8 \text { or } 9\end{array}$ & $\begin{array}{l}\text { Please enter mobile } \\
\text { numbers starting } \\
\text { from } 7,8 \text { or } 9\end{array}$ & Valid \\
\hline \multirow[t]{2}{*}{6.} & \multirow[t]{2}{*}{$\begin{array}{l}\text { Change } \\
\text { Password }\end{array}$} & $\begin{array}{l}\text { Old } \\
\text { Password }\end{array}$ & $\begin{array}{l}\text { New } \\
\text { Password }\end{array}$ & $\begin{array}{l}\text { Confirm } \\
\text { Password }\end{array}$ & \multirow[t]{2}{*}{$\begin{array}{l}\text { Password changed } \\
\text { successfully }\end{array}$} & \multirow[t]{2}{*}{$\begin{array}{l}\text { Password changed } \\
\text { successfully }\end{array}$} & \multirow[t]{2}{*}{ Valid } \\
\hline & & 123456789 & 12341234 & 12341234 & & & \\
\hline 7. & $\begin{array}{l}\text { Forgot } \\
\text { Password }\end{array}$ & \multicolumn{3}{|c|}{$\begin{array}{l}\text { Prithvi } \\
\text { (Click on the given link) }\end{array}$} & $\begin{array}{l}\text { Password sent to } \\
\text { your email address } \\
\text { <email id> }\end{array}$ & $\begin{array}{l}\text { Password sent to } \\
\text { your email address } \\
\text { <email id> }\end{array}$ & Valid \\
\hline 8. & $\begin{array}{l}\text { Password } \\
\text { Length }\end{array}$ & \multicolumn{3}{|c|}{12345678901234567890} & $\begin{array}{l}\text { Password too long. } \\
\text { (Maximum length is } \\
15 \text { characters) }\end{array}$ & $\begin{array}{l}\text { Password too long. } \\
\text { (Maximum length } \\
\text { is } 15 \text { characters) }\end{array}$ & Valid \\
\hline
\end{tabular}

Fig. 6 Test cases

\section{RESULTS AND SCREENSHOTS}

\section{A.SCREENSHOTS}

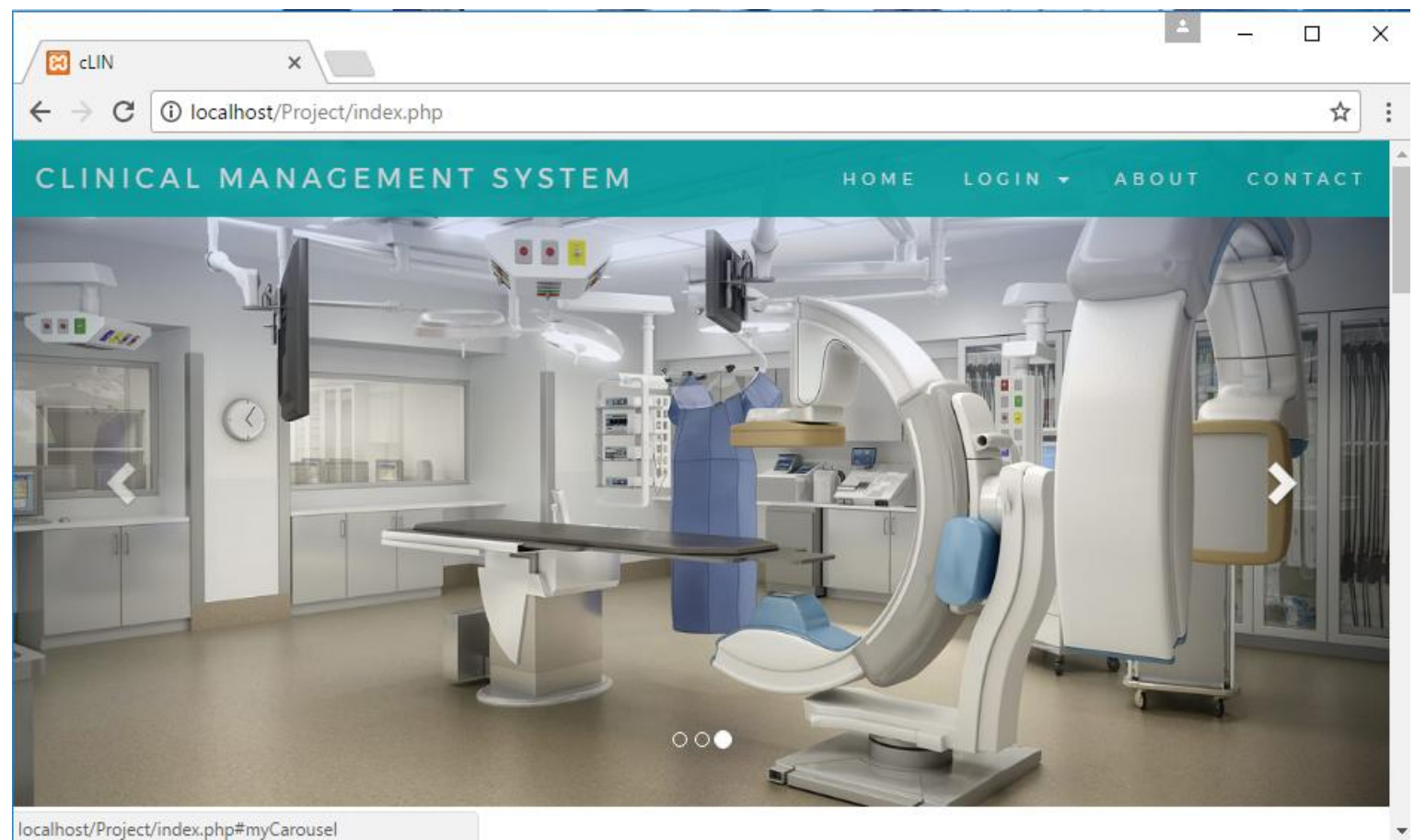

Fig.7 Homepage 


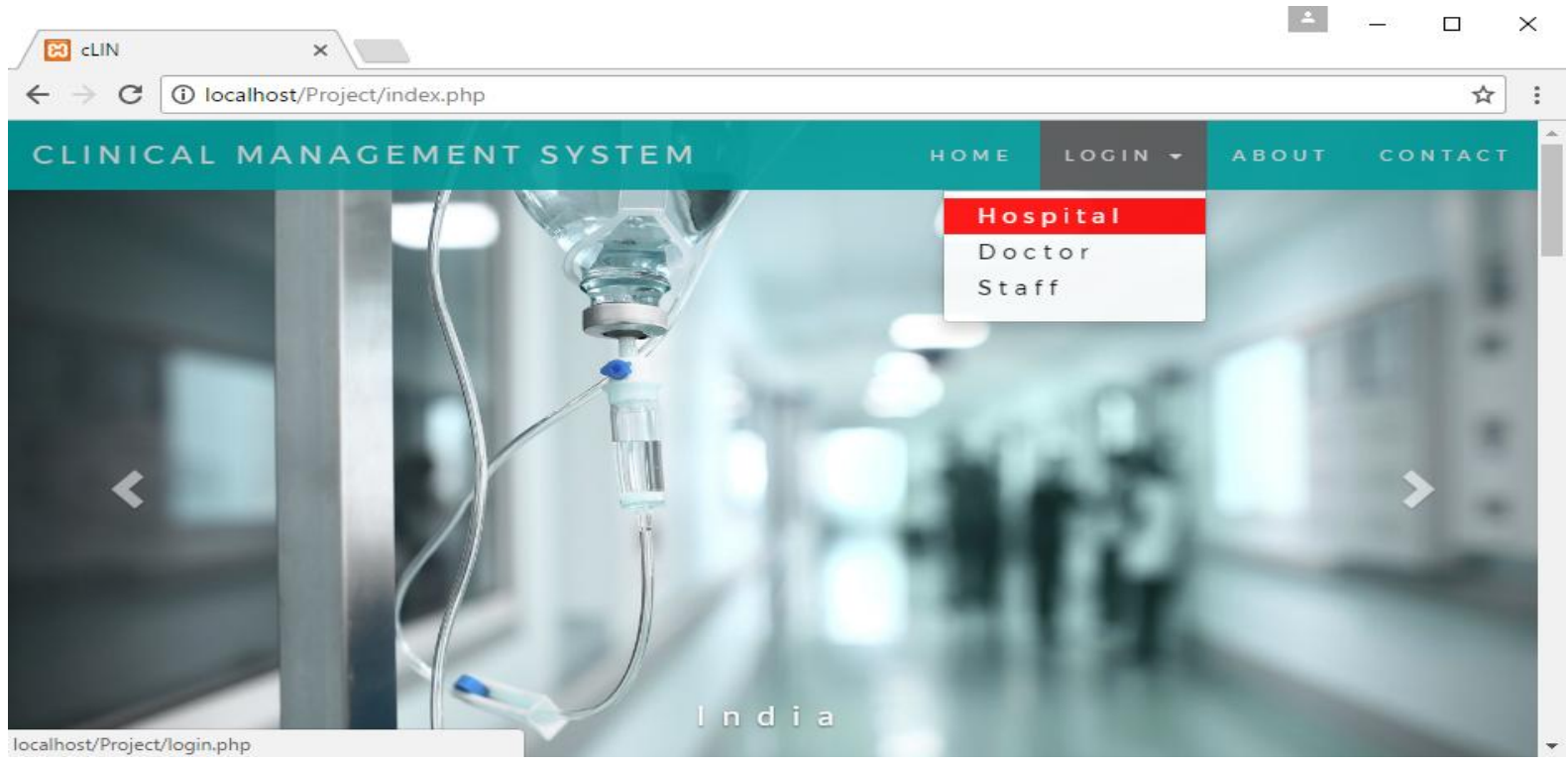

Fig. 8 Login menu

\section{VI.CONCLUSION}

This project implements a web based clinical data management system to automate most of the tasks that were previously done manually in hospitals. This web application which is an automated system to manage the patient records does so in an easy and smooth manner. With the help of this web application, many of the earlier tasks that were done manually are now automated. Resource management is now done in an efficient way with the use of this software. Many petty yet important things like assigning an ID to doctor and patients are also taken care of by the system. On the management point of view, the collection of money for the day, month and year can also be generated. Patient's test reports can be made available to the doctor as soon as the test results are available without much delay. This helps in slightly faster delivery of service to the patients and also reduces the mean time of work done by doctors if many patients are considered. Considering the fact that the reports are also stored on the cloud with triple-encryption, there is more safety and security now to the patient's records and unauthorized access can be prevented. Backups of files are also present in case any printed and stored hardcopy of the report is lost. These features help the hospital administrator, the doctor and the test centre administrators by reducing manual work overload and helping them function smoothly and efficiently.

\section{ACKNOWLEDGMENT}

It has been our immense pleasure to work with Prof. P. V. Tergundi as our guide. We avail of this opportunity to express our deep sense of gratitude for his keen cooperation, guidance and the best support in carrying out our project. He has been our continuous source and spirit of inspiration. Hence it is our bounden duty to offer our gratefulness to him. Prof. P. V. Tergundi has spent his precious time with us to complete the project and through him we have learnt so many things during the completion of our project. We sincerely express our gratitude to our respected Head of Department Dr. S. F. Rodd, and Department of Computer Science \& Engineering for paying kind attention during the completion of the project. We are grateful to our beloved principal Dr. A. S. Deshpande, for providing us with all the facilities which were required for the completion of our project. We take this opportunity to express our deep sense of gratitude towards our beloved parents, friends for providing the inspiration required for taking the project to its completion and for their moral support.

\section{REFERENCES}

[1] Haux R, Knaup P, Leiner F, on educating about medical data management-the other side of the electronic health record.

[2] http://pages.eclinicaos.com

[3] http://www.picronline.org

[4] Krishnankutty, B; Bellary, S; Kumar, NB; Moodahadu, LS (2012). "Data management in clinical research: An overview".

[5] 1sh_clinical_data_management_whitepaper.pdf

[6] Reynolds-Haertle RA, McBride R.single vs. double data entry in CAST.

[7] www.carestream.com

[8] www.cytel.com

[9] http://globalhealth.org 